\title{
ENGRAULÍDEOS BRASILEIROS DO GÊNERO ANCHOVIELLA
}

\author{
J. de Paiva Carvalho
}

Em trabalho anterior (Carvalho 1950, p. 43), tivemos ocasião de fazer referências à confusão reinante na família Engraulidae, situação essa, contudo, mais favorável do que a evidenciada por Thering (1930, p. 2) em relação aos Clupeídeos em geral e por Storey (1938, p. 4), quanto a Harengula em particular. Myers (1940, p. 437), ao examinar manjubas pertencentes às coleções da Universidade de Indiana, encontrou inúmeros exemplares "relacionados eom o grupo denominado Amplova, por Jordan \& Seale", colocando nesse gênero, entre outras, as seguintes espécies: Anchoviella vaillanti (Steind), A. brevirostris (Günther), A. guianensis (Eigenmann) e A. jamesi Jordan \& Seale, ao mesmo tempo que descrevia uma espécie do Perú a que deu o nome de Amplova alleni. Dois anos mais tarde, Eigenmann \& Allen (1942, p. 332-333), diziam: "As espécies que se seguem, foram incluidas no gênero Amplova, mas parece que Hildebrand, na monografia que vai publicar, demonstrará que Amplova, de Jordan \& Seale, não difere de Anchoviella Fowler'”. No que diz respeito a êste gênero, parece já haver uma eerta coneordância nomenclatural por parte dos especialistas, afigurando-se-nos que Hildebrand (1943, p. 1-165) muito contribuiu para a normalização dêsse estado de cousas, com a criteriosa revisão a que submeteu as manjubas americanas. A julgar pelos trabalhos mais recentes, tem-se a impressão de que o grupo está em vias de ser convenientemente investigado. De fato, Fowler (1948, p. 18-24), por exemplo, nos dá perfeita relação das espécies de Anchoviella ocorrentes no Brasil. Êsse trabalho difere sensivelmente do que o autor publicou há oito anos (1942, p. 115-184), no qual Anchoa hepsetus hepsetus figurava como Anchoviella epsetus, Anchovia clupeoides como Anchoviella clupeoides, Anchoa spinifera como Anchoviella spinifera, Anchoa salvadoris como Anchoviella salvadoris, etc. No último trabalho dêsse autor, discordamos, apenas, quanto à A. carrikeri, seguindo Hildebrand (1. c., p. 119) que a considera semelhante a A. brevirostris. Tal critério será seguido por nós até que tenhamos em mãos, material suficiente para estudos comparativos.

Dada a extensão da nossa costa e a ausência de recursos materiais de que nos ressentimos, não será exagerado dizer-se que o estudo dos nossos Engraulídeos está longe de atingir a sua méta final. Com exceção da região litorânea do Est. de S. Paulo, onde houve abundante material, 
sobretudo de Anchoviella hubbsi e A. brasiliensis, pode-se dizer que o norte e o sul do nosso País oferecem ainda campos vastíssimos para a pesquisa.

A questão da distribuição geográfica dos exemplares do gênero Anchoviella, por exemplo, está a exigir cuidados muito especiais. Além de certo número de notas constantes da literatura, indicando sòmente "Rio de Janeiro", "Pará", "Bahia" ou simplesmente "Brasil", como local de proveniência, é bastante reduzido o número de registros absolutamente claros ou que não se prestem a fáceis confusões. Em relação a A. brevirostris, deve-se convir que a descrição original de Günther (1868, p. 392) é inadequada, tendo havido, por um lado, escassez de material da localidade típica e, por outro, provável dilatação da área de expansão geográfica da espécie. Quanto a A. vaillanti, Steindachner (1908, p. 193), dá como localidade típica Joazeiro, situada à margem do rio São Francisco, esclarecendo, no entretanto: "cidade da Barra, Rio Preto, Rio Grande do Norte"'. Trata-se, evidentemente, de engano do autor, êrro que Fowler (1948, p. 22) repete; o registro exato é o seguinte: "Rio Preto, cidade da Barra do Rio Grande (Rio São Franciseo), Bahia". Êste último eurso fluvial deságua no rio São Francisco, entre os povoados de Igaraí e Icatú, nada tendo que ver a ocorrência da espécie com o Estado do Rio Grande do Norte. Neste particular, está certa a referêneia de Myers (1940, p. 439) quando diz: "cidade da Barra, no rio São Francisco, Estado da Bahia'. $́$ É possível que o material tenha sido coletado tanto no rio Preto como no rio Grande.

No tocante à quantidade de espécies tratadas, parece-nos que o trabalho mais importante é o de Hildebrand (1943). Fowler (1942, p. 135), refere-se a Anchoviella manjuba (Ribeiro) e a $A$. producta (Poey). Já tivemos ocasião de mostrar (Carvalho 1950, p. 43) que Stolephorus maryuba Ribeiro foi colocada na sinonímia de Anchoa januaria por Hildebrand \& Carvalho (1948, p. 288), "em virtude da concordância de caractéres com esta espécie e à vista de na descrição original não ter o autor feito menção ao número de rastros existentes, circunstância que seria de valor extraordinário". Quanto a Anchoviella producta, dada como proveniente do Mereado do Rio de Janeiro, não temos por ora, nenhum elemento que nos permita julgar da sua ocorrência em águas cariocas. É de se extranhar, aliás, que Fowler não a tivesse incluído no seu último trabalho, entre as demais espécies do gênero Anchoviella. Supomos, entretanto, que a espécie seja idêntica a Anchovia clupeoides (Swainson), da qual Eigenmann \& Norris (1900, p. 360) encontraram um exemplar, do Est. de São Paulo, medindo $115 \mathrm{~mm}$ de comprimento. Aliás, o porte dêsse espécime concorda perfeitamente com o referido por Hildebrand (1. c., p. 29) e relativo a um exemplar oriundo do lago Rogogagua, Bolívia (N. ${ }^{\circ} 9.398$ da col., da Cal. Acad. Sei.), apesar de diferir dêle por possuir "inserção da barbatana dorsal no meio do corpo. De outra maneira, do que em Stolephorus clupeoides (Swainson)',. É pena que não tenha sido assinalado o local exato de origem do exemplar. Não 
há dúvida, porém, de que se trata de habitante da costa paulista, desde que o trabalho foi baseado "numa coleção de peixes feita pelo Dr. H. von Ihering do Museu Paulista, nas proximidades de São Paulo, em alguns rios que desembocam diretamente no Oceano Atlântico e em outros que são tributários do Paraná. Foram também incluidos alguns peixes marítimos de Santos" (p. 349). Como se vê, a dispersão geográfica de A. clupëiodes parece ser muito grande, tendo sido o seu aparecimento assinalado em Pernambuco, por Swainson (1839) e na Bahia, por Steindachner (1879).

Afigura-se-nos que, com as duas espécies descritas por Hildebrand \& Carvalho (1. e., p. 292-296) e uma terceira apresentada recentemente por êste último autor (Carvalho 1950, p. 76-81), sobe a 12 (doze) o número de exemplares do gênero Anchoviella até agora ocorrentes em águas brasileiras.

Contribuiram muito para o colecionamento de espécimes e obtenção de dados referentes aos exemplares do litoral paulista, os snrs. Franciseo de Paula Andrade Ramos, Dr. Álvaro da Silva Braga, Luiz Chabassus Filho e Prof. Waldomiro Bai Borodin. Somos muito gratos também ao snr. Dr. Raimundo Demócrito Silva, pela remessa que nos fez de alguns exemplares de Vitória e Rio de Janeiro. O material proveniente do rio Paraguaçú, na Bahia, foi enviado por nímia gentileza do nosso muito prezado amigo, snr. Julio Matheus dos Santos. A êsses prestantes colaboradores, aqui fica a expressão mais sincera dos nossos agradecimentos.

A distribuição dos representantes do gênero Anchoviella, de acôrdo com a divisão do território brasileiro em regiões naturais é a seguinte:

I - Região Norte. Estados do Amazonas e Pará, com as seguintes espécie:

a) Anchoviella brevirostris (Günther).

b) Anchoviella guianensis (Eigenmann).

c) Anchoviella jamesi (Jordan \& Seale).

d) Anchoviella nattereri (Steindachner).

II - Região Nordeste, compreendendo o Nordeste Oriental, representado pelo Estado do Ceará, com as seguintes espécies:

a) Anchoviella iheringi Fowler.

b) Anchoviella pallida (Starks).

III - Região Leste, subdividida em:

A - Leste setentrional, representada pala Bahia, com as seguintes espécies:
a) Anchoviella brevirostris (Günther).
b) Anchoviella vaillanti (Steindachner).
c) Anchoviella hildebrandi Carvalho. 
B - Leste meridional, integrada pelos Estados do Espírito Santo, Rio de Janeiro e Distrito Federal, com as seguintes espécies:

a) Anchoviella victoriae Hildebrand \& Carvalho.

b) Anchoviella nitida Hildebrand \& Carvalho.

IV - Região Sul, compreendendo os Estados de São Paulo até o Rio Grande do Sul, com as seguintes espécies:

a) Anchoviella hubbsi Hildebrand.

b) Anchoviella brasiliensis Hildebrand.

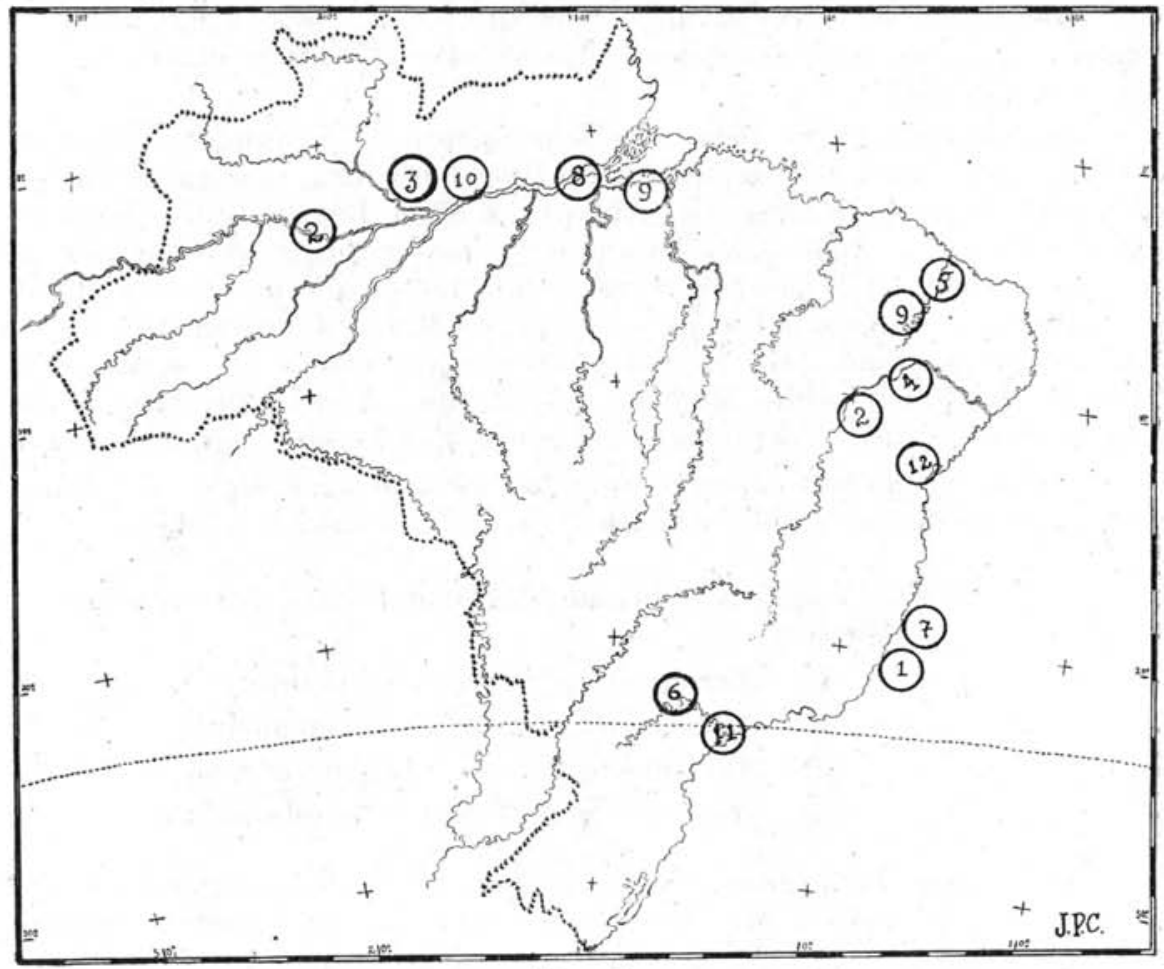

Mapa 1

Distribuição, no Brasil, dos representantes de Engraulídeos do gênero Anchoviella.

Legenda :

1 - Anchoviella victoriae Hildebrand \& Carvalho.

2 - Anchoviella brevirostris (Günther).

3 - Anchoviella guianensis (Eigenmann).

4 - Anchoviella vaillanti (Steindachner).

5 - Anchoviella iheringi Fowler.

6 - Anchoviella hubbsi Hildebrand.

7 - Anchoviella nitida Hildebrand \& Carvalho.

8 - Anchoviella nattereri (Steindachner).

9 - Anchoviella pallida (Starks).

10 - Anchoviella jamesi (Jordan \& Seale).

11 - Anchoviella brasiliensis Hildebrand.

12 - Anchoviella hildebrandi Carvalho. 
Para maior facilidade do estudo, elucidamos a situação das localidades típicas no Mapa n. ${ }^{\circ} 1$, apresentando as espécies de acôrdo com a sequência decorrente dos caractéres constantes da chave de classificação que, como aconteceu em relação aos representantes do gênero Anchoa, é a mesma organizada por Hildebrand, (l, c., p. 109-111), adaptada às espécies nacionais.

José Verissimo (1895, p. 169) já se referira, com muito acêrto, ao problema econômico da pesca, escrevendo: "Na Amazonia, como por todo o Brazil, a estatística não sae da sua enfezada infancia; é pobre, deficiente e mal feita". Dois anos mais tarde Thering (1897, p. 54), depois de estudar a fauna marítima do R. G. do Sul, dizia: "Será assunto de suma importancia conhecermos melhor estas migrações dos peixes costeiros. Desejo que estas linhas contribuam para que sejam feitas observações exatas e estatísticas sôbre o. número e os mezes de aparecimentos dos peixes maritimos".

Tais anseios, manifestados de Norte a Sul do nosso País, até hoje não se concretizaram. Mais de meio século após terem sido pronunciadas tão sábias palavras, encontramo-nos ainda com os nossos trabalhos estatísticos em fase de "enfezada infância". Muito pouco, infelizmente, se sabe a respeito da migração dos nossos peixes costeiros e não se pode, com segurança, avaliar o que êles realmente significam na nossa balança comercial (1).

No excelente trabalho que publicou sôbre o vale do rio São Franciseo, Moraes Rego (1936, p. 610), apesar de dizer que "talvez as águas da bacia do São Franciseo sejam as mais piscosas do Brasil" e depois de assinalar a falta, na região, de certos representantes da fauna ictiológica do Amazonas, faz menção especial ao Surubim, ao Dourado, aos Curimbatás, às Piranhas e às Traíras, não se referindo a espécimes de menor porte. Diz ainda o autor (p. 689) que "a pesca sustenta grandemente a população ribeirinha"; acrescenta que "conservam algum pescado por processos rudimentares e exportam-no até certa distância", afirmando que "têm sido feitas tentativas para a conserva e exportação do pescado em larga escala".

Nessa região, contudo, conforme assinala Magalhães (1942, p. 15), "pesca-se no rio e seus afluentes, mas a riqueza piscícola, vultuosa, é a das lagoas" que, segundo o mesmo autor (p. 16) costuma ser extraída 'quando as águas começam a baixar, isto é, em começo de abril e prolongase até agôsto ou meados de setembro".

(1) Louvável e oportuníssima foi, portanto, a atividade desenvolvida pela "Sociedade Brasileira para o Progresso da Ciência", no sentido de incentivar o estudo da Estatística, por meio de reuniões, eonferêneias e cursos. O primeiro passo decisivo nesse sentido parece ter sido dado pela Divisão de Experimentação e Pesquisas, do Instituto Agronômico, de Campinas, na Primeira Série dos Seminários de Estatística Aplicada (1949, p. 1-97). Segue-se o recente trabalho de Stevens (1950, n. 17-28), apresentado à primeira reunião da S. B. P. C., realizada em Outubro de 1949, em que se discutiram os principais fundamentos do planejamento de experiêneias. 
Ainda em nossos dias, tal critério predomina. Haja vista, por exemplo, o apreciável trabalho de Le Cointe (1945, p. 148) sôbre o Pará, em que o autor coloca entre os exemplares notáveis "pelo seu sabor", "o peixe que chamam Sardinha (Agoniates ou Chalceus esp. div.), mas ambos têm a carne recheada de espinhas. Pegam-se de tarrafa nas épocas de "piracema", isto é, quando baixando as águas os peixes vão subindo contra a correnteza, costeando as margens do rio".

A mesma cousa se pode dizer quanto às regiões do nordeste, leste $\mathrm{e}$ sul, onde a pobreza de dados é enorme. Da região leste setentrional e em relação à espécie Anchoviella hildebrandi, só obtivemos informações de que, no rio Paraguaçú, ela é capturada e vendida em estado freseo para o consumo local das populações ribeirinhas; é ainda enviada ao mereado da Bahia sob as formas de peixe sêco e salgado, aparecendo em janeiro e julho sob a de peixe assado.

Em São Paulo, porém, um exemplar do gênero Anchoviella A. hubbsi Hildebrand, representa não só papel de relevante importância na alimentação das populações ribeirinhas, mas constitue também produto de grande valor econômico para tôda a zona do rio Ribeira de Iguape. Carvalho \& Ramos (1943, p. 38-59) já tiveram ocasião de se manifestar sôbre o assunto, estudando a produção dos anos de 1938 a 1940. Quando, em 1935, êsses autores deram início aos trabalhos no litoral sul, a produção não chegava a $200.000 \mathrm{~kg}$. Em 1938, constatou-se a existência de $350.000 \mathrm{~kg}$. que atingiu a $570.000 \mathrm{~kg}$. em 1939 e $540.000 \mathrm{~kg}$. em 1940 . Tais dados foram colhidos nos próprios portos de pesea, devendo, contudo, ser considerados como cifras aproximadas. $O$ contrôle cingiu-se ao exame das guias de embarque da Companhia Fluvial Sul Paulista, delas não figurando, naturalmente, as partidas enviadas ao consumo do nosso hinterland, por meio de barcos de pesca, embarcações de pequena cabotagem e veículos motorizados que, pelas rodovias, demandavam os centros consumidores mais afastados.

A abundâneia da matéria prima era notória, contrastando com o seu preço irrisório. Em 1935, por exemplo, na eidade de Registro, uma lata das de gasolina com, aproximadamente, $40 \mathrm{~kg}$. de peixe fresco, era vendida para o consumo caseiro, à razão de $\mathrm{Cr} \$ 6,00$. Um ano mais tarde, o preço de quilo subia a Cr\$ $\$, 00$ e Cr\$ $\$ 10,00$ o que já representava eusto apreeiabilíssimo. Presentemente, o preço médio de uma caixa com $20 \mathrm{~kg}$. é de Cr\$100,00. A quantidade da matéria prima era incrível, não havendo nenhum exagêro da parte daquêles que apregoavam a existência, no litoral sul, de uma riqueza imensa que, quando bem dirigida, poderia ser objeto de excelente aproveitamento comercial e industrial. Basta dizer que o produto, por falta de meios adequados de transporte, era empregado como adubo na lavoura. Hoje em dia, naquela cidade, o custo do quilo de manjuba fresca, no varejo, é de Cr\$ 4,00, vendendo-se o produto para consumo imediato.

Com muita razão diz Teixeira (1950) que 'a sardinha importada poderia ser perfeitamente substituida pela que existe no litoral de 
São Paulo", acrescentando ocorrer "um peixe muito semelhante à Sardinha, que é a manjuba e que, bem preparada em conserva, nada fica a dever ao produto importado, apesar de ser menor o seu tamanho".

Analisando-se os dados constantes do "Anuário da Pesca Marítima no Estado de São Paulo", correspondente a 1944 (p. 12-13 - 58-59), verifica-se que o total de manjubas frescas e manipuladas, naquêle ano, foi o seguinte:

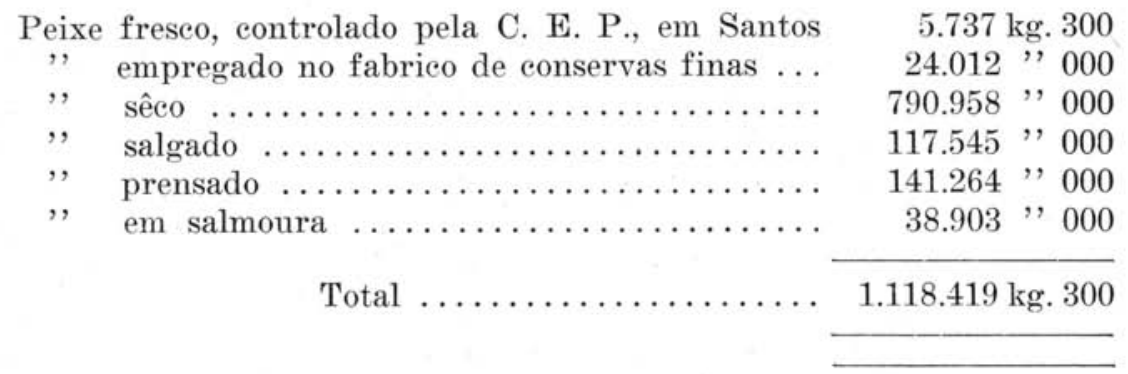

Dêsse total, a maior contribuição foi a da zona central, com 141.264 quilos de "peixe prensado". Segue-se o "peixe salgado", com $56.212 \mathrm{~kg}$. na zona Central, $45.474 \mathrm{~kg}$. na zona Norte e $15.859 \mathrm{~kg}$. na zona Sul. Vem depois o "peixe sêco", com $735.887 \mathrm{~kg}$. na zona Sul, $48.912 \mathrm{~kg}$. na Norte e $6.159 \mathrm{~kg}$. na Central. De menor importância figura o pescado "em salmoura", com $27.727 \mathrm{~kg}$. na zona Central e $11.176 \mathrm{~kg}$. na zona Sul. A parte menos volumosa coube justamente à indústria de "conservas finas", que contou com uma única fábrica hoje paralizada, mas que funcionou na cidade de Iguape e euja produção foi de $24.012 \mathrm{~kg}$.

Por aí se vê que o grosso da produção de engraulídeos, no Estado de São Paulo, é representado, em primeiro lugar, pelo peixe sêco, seguindo-se-lhe o produto prensado e, em terceiro lugar, o salgado.

As principais espécies empregadas na manipulação comercial e industrial, no litoral bandeirante, são as seguintes:

Anchoviella hubbsi Hildebrand.

Zona Sul Anchoviella brasiliensis Hildebrand.

Anchoa januaria (Steindachner). (*)

(Anchoa januaria (Steindachner).

Zona Central Anchoa marinii Hildebrand.

Engraulis anchoita Hubbs \& Marini. (*)

Anchoa nasuta Hildebrand \& Carvalho.

Zona Norte Engraulis anchoita Hubbs \& Marini.

Anchoa ubatubae Hildebrand \& Carvalho. (*)

(*) Ocorrência eventual. 
Na confecção do presente trabalho, contamos com a preciosa colaboração do snr. Dr. Samuel F. Hildebrand, do Fish \& Wildlife Service, de Washington. Utilizamo-nos da chave de classificação por êle organizada para os Engraulídeos americanos (p. 11-12), adaptada aos exemplares que frequentam as águas brasileiras, como segue:

a) Membranas das guelras quase ou totalmente separadas do istmo, nunca a êle totalmente ligadas.

b) Todos os dentes das mandíbulas, diminutos, quase do mesmo tamanho.

c) Anal originando-se sempre em ponto posterior ao do de origem da dorsal, muito raramente atrás dela; rastros longos, estreitos, pontudos, mais ou menos numerosos, quase sempre em quantidade superior a 15, no ramo inferior do primeiro areo branquial; espécies dotadas de pórte médio.

d) Corpo delgado, fortemente comprimido; número de vértebras raramente superior a 46 ; nadadeira anal grande ou pequena, originando-se frequentemente sob e em algum ponto da base da dorsal, situada excepcionalmente atrás dela.

e) Maxilar de tamanho médio, um tanto largo, geralmente não atingindo a articulação da mandíbula, nunca ultrapassando-a, com a porção posterior quadrada ou fortemente arredondada, jamais terminando em ponta. Exemplares de pórte médio, exibindo tamanho inferior a $150 \mathrm{~mm}$........... Anchoviella.

\section{Gênero Anchoviella Fowler, 1911}

O gêrero teve por tipo Engraulis perfasciata Poey, de Cuba. Distingue-se de Anchoa, sobretudo, por possuir maxilar mais curto, de largura muito variável, com a extremidade posterior quadrada ou errodondada, podendo atingir mas nunca ultrapassar a articulação da mandíbula. O corpo é alongado e comprimido, quase sempre dotado de linha lateral prateada evidente.

Conforme se depreende do mapa de fls. 44, a região Norte do Brasil é a mais bem dotada de espécimes, ocorrendo 3 no Amazonas e 2 no Pará. Segue-se a região do Nordeste, a Leste Setentrional, Leste meridional e Sul, cada uma com duas espécies. Tôdas penetram em cursos fluviais, vivendo algumas em ambiente de água doce e lagos muito afastados do Oceano.

As maiores espécies são Anchoviella hubbsi Hildebrand e A. victoriae Hildebrand \& Carvalho, figurando entre as menores A. jamesi (Jordan \& Seale) e A. guianensis (Eigenmann). 


\section{Chave para a determinação das espécies brasileiras}

a) Maxilar de tamanho moderado, ultrapassando muito a margem posterior da órbita.

b) Anal originando-se sob a metade posterior da base da dorsa algumas vêzes situada um pouco mais atrás; rastros do ramo superior do primeiro areo branquial, em número inferior a 24 , variando de 29 a 33 , no ramo inferior.

c) Nadadeira anal, curta, com 15 a 20 raios; dorsal originando-se em ponto quase equidistante da base da caudal e da ponta do focinho.

d) Bôca ampla; maxilar contido cêrea de 1.4 a 1.65 na cabeça; peitoral curta, deixando de atingir a base da ventral por um espaço igual ou pouco maior do que o diâmetro do ôlho, contida de 1.25 a 2.5 na eabeça e de 5.6 a 8.2 no comprimento "standard".

e) Rastros mais ou menos numerosos, figurando 21 a 23 no ramo superior e 29 a 33 no inferior; peitoral com 14 a 16 raios.

f) Anal originando-se atrás da vertical baixada da base do último raio da dorsal; escama axilar da peitoral, comprida e delgada, deixando de atingir a ponta da nadadeira por uma distância igual à do diâmetro da pupila e contida de 1.45 a 1.6 na cabeça $\ldots \ldots \ldots \ldots \ldots \ldots \ldots \ldots \ldots \ldots \ldots \ldots \ldots \ldots \ldots \ldots \ldots$ victoriae.

ee) Rastros menos numerosos, figurando de 12 a 14 no ramo superior e 18 a 20 no inferior.

g) Corpo mais ou menos delgado, com altura contida de 5.3 a 6.3 no comprimento "standard"; ôlho grande, contido de 3 a 3.5 vêzes na eabeça; peitoral com 11 ou 12 raios ... brevirostris.

dd) Bôca não muito ampla; maxilar contido de 1.6 a 1.9 na cabeça; peitoral mais ou menos longa, deixando de atingir a ventral por uma distância igual ao diâmetro da pupila e contida de 1.4 a 1.6 na cabeça e de 5.9 a 6.4 no comprimento "standard"; rastros em número de 16 a 18 , no ramo superior e de 23 a 26 no inferior; peitoral com 12 ou 13 raios.

h) Maxilar de comprimento moderado; bochechas mais ou menos longas, quase da largura da órbita, formando ângulo posterior de $60^{\circ}$; ôlho grande, contido de 3.2 a 3.5 na cabeça; escama axilar da peitoral um tanto curta, atingindo e, não raro, ultrapassando um pouco o meio da nadadeira, contida de 2.4 a 2.9 na cabeça; presença de lista escura mediana na região posterior da anal $\ldots \ldots \ldots \ldots \ldots \ldots \ldots \ldots \ldots \ldots \ldots \ldots \ldots \ldots \ldots \ldots$ guianensis.

ce) Nadadeira anal mais comprida, com 22 a 25 raios; dorsal originando-se em local mais próximo da ponta do focinho do que da 
base da caudal; rastros em número de 18 ou 19 no ramo inferior do primeiro areo branquial; peitoral quase atingindo a base da

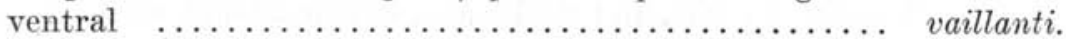

ece) Nadadeira anal com 24 a 26 raios; rastros em número de $14+19$; dorsal originando-se em ponto quase equidistante da margem anterior da órbita e da base da eaudal; anal situada um poueo adiante da vertical baixada sob o meio da dorsal ........... iheringi.

bb) Anal originando-se sob e adiante do meio da base da dorsal, provida de 22 a 29 raios.

i) Rastros não muito numerosos, existindo quase sempre 21 ou menos no ramo superior e 30 ou menos, no inferior; altura contida 4 ou mais vêzes no eomprimento "standard".

j) Anal um tanto curta, com 22 a 27 raios; peitoral curta, não atingindo a base da ventral.

k) Cabeça grande, contida de 4 a 4.3 vêzes no comprimento "standard"; dentes mais ou menos grandes; rastros em número de 18 a $20+23$ ou 24 ; lista lateral prateada mais estreita do que a órbita, acima da base da anal, sem tarja escura na porção

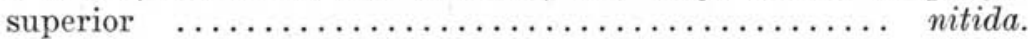

kk) Cabeça menor, contida de 4.3 a 4.7 no comprimento "standard"; dentes menores; rastros em número de 17 a $21+19$ a 25 ; lista lateral prateada da largura da órbita, com a porção superior tar-

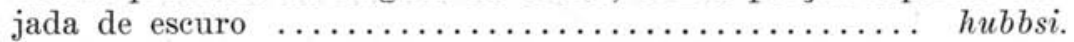

ecec) Nadadeira anal com 28 ou 29 raios; peitoral atingindo o meio da ventral; altura contida 4 vêzes no comprimento "standard" ...................................... nattereri.

ii) Rastros mais numerosos, figurando 28 a $34+36$ a 45 ; corpo um tanto fortemente comprimido; altura contida de 3.5 a 3.9 vêzes no comprimento "standard"; nadadeira peitoral longa, ultrapassando a base da ventral $\ldots \ldots \ldots \ldots \ldots \ldots \ldots \ldots$ pallida.

aa) Maxilar muito eurto e largo posteriormente, ultrapassando apenas a orla posterior da órbita, por distância inferior ao diâmetro da pupila.

1) Anal com 19 a 22 raios; rastros em número de 12 a $20+20$ a 25 ; altura contida de 4.1 a 6.1 no comprimento "standard"; cabeça contida de 3.9 a 4.6 no comprimento "standard".

m) Focinho contido 7.2 no eomprimento da cabeça; maxilar 1.2 a 2 vêzes na cabeça; peitoral com 11 raios, contida 5.4 a 6.5 no comprimento "standard", mal atingindo a origem da ventral; dorsal com 12 a 13 raios .................... jamesi.

$\mathrm{mm}$ ) Focinho contido de 3.75 a 5.8 no comprimento da cabeça; maxilar 1.6 a 1.8 na cabeça; peitoral com 13 a 15 raios, deixando de 
atingir a ventral por distância superior à que vai da ponta do focinho até à margem posterior da órbita; dorsal com 17 a 18

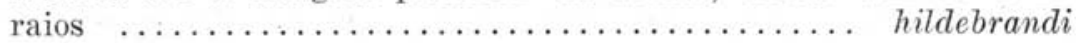

mímm) Focinho contido de 5.4 a 5.7 no comprimento da cabeça; maxilar 1.65 a 1.7 na eabeça; peitoral com 14 a 15 raios, deixando de atingir a ventral por distância igual à metade do diâmetro do ollho; dorsal com 12 a 13 raios .............. brasiliensis.

Seguimos Hildebrand (1943, p. 8-9) na obtenção de medidas e proporȩões bem como nas contagens em geral.

Anchoviella victoriae Hildebrand \& Carvalho

Est. I, fig. 1

Anchoviella victoriae Hildebrand \& Carvalho 1948, p. 292-294.

Cabeça 4.3 a 4.5 no comprimento "standard"; altura 5.5 a 5.95 ; D. 15 ou 16 ; A. 16 ou 17 ; P. 14 a 16 ; vértebras 42 .

Corpo um tanto delgado, de linhas robustas mas elegantes, com altura contida de 5.5 a 5.95 no comprimento "standard". Perfil ventral um pouco mais convexo do que o dorsal. Cabeça mais ou menos grande, com altura, na articulação da mandíbula, quase igual ao comprimento posterior e contida de 4.3 a 4.5 no comprimento "standard". Bôca de tamanho moderado, armada de dentes miúdos; maxilar com a porção distal mais ou menos expandida e arredondada, não atingindo a articulação da mandíbula por espaço quase igual ao diâmetro da pupila e contido de 1.55 a 1.65 vêzes na eabeça e de 6.7 a 7.2 vêzes no comprimento "standard"; mandíbula contida de 6.4 a 6.7 no comprimento "standard". Focinho mais ou menos embotado, muito mais curto do que o diâmetro do ôlho e contido de 4.65 a 5.25 na eabeça; narinas pequenas, anteriores. Olho um tanto grande, contido de 3.35 a 3.6 vêzes na cabeça e de 1.7 a 1.85 na porção post-orbital da cabeça. Opéreulo normal, amplo, formando ângulo na direção da parte superior da escama axilar; porȩão post-orbital de cabeça curta, contida de 8.5 a 8.7 vêzes no comprimento "standard"; bochechas um pouco menores do que o ôlho, com ângulo posterior de $60^{\circ}$. Rastros medindo $2 / 3$ do comprimento do ôlho, com serrilhas fortes na margem interna e a fórmula 21 a $23+29$ a 33 , no primeiro areo branquial. Peitoral com 14 a 16 raios, de tamanho moderado, terminando em ponta, deixando de atingir a ventral por distância igual ao diâmetro do ôlho, inserida quase em ponto equidistante da ponta da mandíbula e da base da ventral, contida de 1.25 a 1.24 na eabeça e de 5.6 a 6 vêzes no comprimento "standard"; eseama axilar da peitoral delgada, pontuda, 
não atingindo a extremidade da nadadeira respectiva, por distância igual ao diâmetro da pupila e contida de 1.4 a 1.6 na cabeça. Ventral um tanto pequena, situada mais perto da base da peitoral do que da anal, contida de 2.1 a 2.5 na eabeça. Dorsal mais ou menos elevada anteriormente, com a margem livre eôncava, originando-se em ponto mais próximo da base da caudal do que da ponta do focinho, o maior raio não atingindo a extremidade do raio mais longo quando a nadadeira se encontra defletida; presença de 15 a 16 raios. Anal com 16 a 17 raios ligeiramente elevada anteriormente, curta, com a margem livre côncava, tendo o seu ponto de origem bem atrás da vertical baixada do último raio da dorsal; contida de 7.5 a 8.5 vêzes no comprimento "standard". Caudal ampla, bem furcada, provida de lóbulos iguais terminando em ponta, existindo uma área escura na base do lóbulo superior.

Colorido branco ou creme; lados da cabeça de colorido prateado brilhante; linha mediana do dorso com pontuações escuras, sobretudo atrás da cabeça e logo depois da nadadeira dorsal. Faixa lateral prateada quase da largura do ôlho, acima da base da anal e com a porção superior enegrecida.

Comprimento total de 105 a $115 \mathrm{~mm}$.; comprimento "standard" de 87 a $97 \mathrm{~mm}$.

Distribuição geográfica: A espécie, até o presente, só foi assinalada em Vitória, no Est. do Espírito Santo.

Tipo figurando sob n. ${ }^{0}$ 143.901, na coleção do U. S. Nat. Museum, dos Estados Unidos:

\section{Anchoviella brevirostris (Günther)}

Est. I, fig. 2

Engraulis brevirostris Günther 1868, p. 392 ; Stolephorus brevirostris Eigenmann \& Eigenmann 1891, p. 63; Amplova brevirostris Myers 1940, p. 440 ; Anchoviella carrikeri Fowler 1941, p. 73, fig. 28; Anchoviella carrikeri Campos 1941, p. 205; Anchoviella brevirostris Hildebrand 1943, p. 119-120; Anchoviella brevirostris Fowler 1948, p. 20.

Cabeça contida de 4.3 a 4.8 vêzes no comprimento "standard"; altura 4.7 a 5 ; D. 14 ; A. 18 ; escamas em número de 33 a 36 , firmes, aderentes e bem imbricadas.

Corpo robusto mas dotado de linhas elegantes, lateralmente comprimido, com a porção anterior mais larga do que a posterior; altura contida de 4.7 a 5 vêzes no comprimento "standard". Perfil dorsal quase idêntico ao ventral; a zona anterior da linha do dorso é sensivelmente mais elevada do que a posterior à nadadeira dorsal. Cabeça relativamente 
pequena em comparação com o corpo e contida de 4.3 a 4.8 vêzes no comprimento "standard". Bôca de tamanho moderado, armada de dentes pequenos, dispostos em uma única série; maxilar com a porȩão distal mais expandida; mandíbula muito eurta; focinho pequeno, não muito rombudo, contido de 1.24 a 1.45 na eabeça; narinas situadas superiormente, em relação à ponta do focinho. Ôlho pequeno, sensìvelmente maior do que o focinho, contido de 3.8 a 4 vêzes na cabeça. Opéreulo normal e amplo, as margens compostas de linhas onduladas. Porȩão post-orbital da cabeça, larga. Bochechas um pouco maiores do que o diâmetro do ôlho, sem ângulo posterior bem definido. Rastros em número de $13+14$ ou 15 no ramo inferior do primeiro areo branquial. Peitoral com 12 raios, de tamanho moderado, contida cêrea de 2.6 vêzes na eabeça. Escama axilar da peitoral muito pequena e pontuda, com a base larga e a extremidade tocando além do terȩo anterior da nadadeira e quase do tamanho do ôlho. Ventral pequena, provida de escama axilar situada mais próxima da base da anal do que da ponta da peitoral. Dorsal com dois a três acúleos, mais 10 ou 11 raios flácidos (14), anteriormente elevada, originando-se em ponto sensìvelmente mais próximo da ponta do focinho do que da base da caudal, com bainha escamosa na base. Anal eurta, com 3 acúleos, mais 14 ou 15 raios, originando-se em ponto posterior ao fim da base dorsal, provida de larga bainha. Caudal ampla, bem fureada, com lóbulos pontudos e em pequena parte da base encoberta de escamas.

Colorido branco leitoso, com os lados da cabeça prateados brilhantes. Faixa lateral prateada bem definida, mais estreita nas proximidades do opéreulo, alargando-se na porȩão caudal.

Comprimento "standard" de 50 a $66 \mathrm{~mm}$.

Distribuição geográfica: ocorre em água doce, no rio Amazonas (Tefé) e na Bahia (Caxoeira) bem como no rio Piaú, tributário do rio Paranaíba.

\title{
Anchoviella guianensis (Eigenmann)
}

\author{
Est. I, fig. 3
}

\begin{abstract}
Amplova guianensis Myers 1940, p. 440; Anchoviella guianensis Hildebrand 1943, p. 122-124; Anchoviella guianensis Fowler 1948, p. 20.
\end{abstract}

Cabeça contida de 4 a 4.2 vêzes no eomprimento "standard"; altura de 5 a 5.6 vêzes; D. 13 ou 14 ; A. 18 ou 19 ; P. 12 ; escamas de 38 a 40.

Corpo um tanto delgádo, longo e comprimido lateralmente, sobretudo no tórax e no abdomen onde a earena não é muito pronunciada; altura do corpo contida de 5 a 5.6 vêzes no comprimento "standard". Perfil ventral bem mais convexo do que o dorsal acentuando-se, sobretudo, tal convexidade, na região toráxica. Cabeça um tanto curta e elevada na região situada acima dos olhos, com altura, na articulação da mandí- 
bula, quase igual à porção post-orbital da eabeça e à metade do ôlho. Bôca ligeiramente oblíqua, armada de dentes diminutos. Maxilar curto, sua extremidade posterior não atingindo a articulação da mandíbula por distância igual a cêrea da metade da largura da pupila. Mandíbula contida de 7.1 a 7.2 vêzes no comprimento "standard". Focinho eurto, com cêrea da metade do seu comprimento avançando além da extremidade da mandíbula e contido de 4.9 a 5.2 na eabeça. Ôlho pequeno, contido de 3.2 a 3.5 vêzes na cabeça. Opéreulo normal, mais ou menos amplo, descendo com margem quase reta a partir do meio da faixa lateral para encurvar-se, logo a seguir, na direção da região gular, nas proximidades da escama axilar da peitoral. Porção post-orbital da eabeça mais ou menos curta, contida de 7.2 a 9 vêzes no comprimento "standard". Bochechas um tanto amplas, com ângulo post-orbital de $60^{\circ}$. Rastros muito pequenos, com a fórmula $16-17+23-24$, no ramo inferior do primeiro areo branquial. Peitoral com 12 raios e forma mais ou menos alongada, deixando de atingir o ponto de partida da ventral, por espaço igual ao do diâmetro da pupila e contida de 1.45 a 1.50 vêzes na cabeça e de 6.5 a 6.9 no comprimento "standard"; raios superiores providos de pequenas máculas ou pontos eseuros. Escama axilar da peitoral delgada, um tanto estreita, com a ponta ultrapassando muito o meio da nadadeira e contida de 2.4 a 2.5 vêzes na çabeça. Ventral originando-se bem em frente do ponto de inserção da dorsal, mais ou menos ampla, originandose em ponto equidistante da base da peitoral e do ponto em que se inicia a anal. Dorsal com 13 ou 14 raios, provida de margem livre mais ou menos côncava, havendo depressão mais acentuada a partir do $8 .^{\circ}$ ou $9 .^{\circ}$ raio ; origem da dorsal em ponto equidistante da extremidade do focinho e da base da caudal; presença de pontuações escuras na nadadeira. Anal, com 18 ou 19 raios, mais ou menos curta, originando-se sob ou um pouco adiante do término da dorsal, com base contida de 6.5 a 6.7 no comprimento "standard"; margem livre da anal, côncava, com a primeira reentrância à altura do $1 .^{\circ}$ e $4 .^{\circ}$ raio anterior e a segunda, mais acentuada, entre o $88^{\circ}$ e o $18 .^{\circ}$ ou $19 .^{\circ}$ raio posterior. Caudal mais ou menos ampla e bem furcada, provida de pontuações escuras.

Colorido creme; lados da cabeça prateados; dorso com pontuações escuras que se acentuam mais entre a dorsal e a caudal. Faixa lateral prateada quase da largura do ôlho, conservando essa largura, da porção posterior da eabeça até o fim do pedúnculo eaudal.

Comprimento total de 50 a $62 \mathrm{~mm}$.

Distribuiẹão geográfica: Itacoatiára; Lagoa Grande (Amazonas).

\section{Anchoviella vaillanti (Steindachner)}

Anchovia vaillanti Starks 1913, p. 10 ; Anchovia vaillanti

Ihering 1930, p. 13; Amplova vaillanti Myers 1940,

p. 429 ; Anchoviella vaillanti Hildebrand 1943 , p. $125-$

126; Anchoviella vaillanti Fowler 1948, p. 22-24. 
Assinalamos a presente espécie que foi vista por Myers (1940, p. 439) na coleção da "Indian University (hoje na California Academy of Science)", proveniente da cidade da Barra, no rio São Francisco. Não nos foi possível obter material para estudo. Assim sendo, seguimos Hildebrand (l. c., p. 125), transerevendo o que foi por êle condensado da descrição de Steindachner, feita em 1908.

"Cabeça 3.6 a cêrea de 4 ; altura 4.35 a 4.8 ; D. 12 ou 13 ; A. 22 a 25 ; escamas 35 a 38 ; ôlho 3.65 a 4.4 na eabeça; focinho 4.65 a 5.5 ; maxilar, nas proximidades da articulação da mandíbula, arredondado; rastros mais curtos do que o ôlho, existindo 18 ou 19 no ramo inferior do primeiro areo; origem da dorsal sempre à frente do meio do corpo, excetuada a caudal; origem da anal sob a base do último raio da dorsal; peitoral quase atingindo a base da ventral. Presença de faixa lateral cinzento prateada, bem evidente; traço escuro ou mancha na base caudal'".

Distribuição geográfica: Joazeiro, cidade da Barra (rio S. Francisco), rio Preto.

\title{
Anchoviella iheringi Fowler
}

\author{
Est. I, fig. 4
}

Anchoviella iheringi Fowler 1941, p. 124; Anchoviella iheringi Fowler 1948, p. 22; Anchoviella iheringi Hildebrand \& Carvalho 1948, p. 292.

Cabeça contida de 3.8 a 4.2 no comprimento "standard"; altura de 4.75 a 5 vêzes; focinho de 5 a 5.2 na cabeça; ôlho de 3 a 3.2 ; D. 15 ; A. 23 a 26 ; P. 13 ; escamas 33 .

Corpo alongado, um tanto adelgaçado mas robusto, com altura contida de 4.75 a 5 vêzes no comprimento "standard". Perfil dorsal quase idêntico ao ventral, sendo êste ligeiramente mais convexo. Escamas em número de 32 a 33 . Cabeça mais ou menos grande, com altura contida de 3.8 a 4.2 vêzes no eomprimento "standard". Bôca bem rasgada, com fenda ampla, armada de dentes pequenos, dispostos em série única. Maxilar de largura moderada, quase atingindo a orla do preopéreulo, com comprimento contido de 1.2 a 1.25 na cabeça. Focinho curto, menor do que o ôlho, com as duas margens convexas, formando ponta levemente acentuada e contido de 5 a 5.2 vêzes na eabeça; narinas pequenas, superoanteriores. Olho grande, situado mais próximo do perfil superior da cabeça do que do maxilar, maior do que o focinho e contido de 3 a 3.2 vêzes na cabeça. Opéreulo normal, amplo. Porẹão post-orbital da eabeça mais ou menos longa. Bochechas posteriormente limitadas pela margem preopéreular, de âmbito mais ou menos restrito. Rastros lanceolados, delgados, em número de $14+19$, no ramo inferior do primeiro areo branquial. Peitoral pequena, com 13 raios, os maiores não atingindo o ponto 
de origem da ventral, achando-se a nadadeira defletida. Escama axilar da peitoral, comprida, com a base larga e a ponta um tanto recurvada para baixo, atingindo o terȩo posterior distal da nadadeira. Ventral pequena, com 7 raios, originando-se em ponto situado bem à frente do de origem da dorsal, mais próximo da extremidade de focinho do que da base da caudal. Dorsal não muito elevada, com 15 raios, a margem livre mais ou menos côncava, havendo depressão um tanto acentuada a partir do $7 .^{\circ}$ raio, eom estojo escamoso na base, originando-se mais ou menos no ponto médio entre a ponta do focinho e a base da caudal. Anal com 24 a 26 raios, mais ou menos eurta, originando-se um pouco atrás da réta baixada do ponto de inserção da dorsal, com a margem livre quase réta, tendo na base um estojo escamoso. Caudal ampla, bem furcada, com os lóbulos terminando em ponta aguda e base fortemente escamosa.

Colorido creme uniforme, com os lados da cabeça prateados, brilhante, o mesmo acontecendo com os bochechas e o opéreulo. Faixa lateral prateada um tanto fôsca, larga junto ao opéreulo e estreita no pedúnculo caudal; fimbrias das nadadeiras um tanto cinzento escuras.

Comprimento total: 80 a $100 \mathrm{~mm}$.

Distribuição geográfica: Ceará (Rio Jaguaribe).

\section{Anchoviella nitida Hildebrand \& Carvalho}

Est. I, fig. 5

\section{Anchoviella nitida Hildebrand \& Carvalho 1948, p. 294-296.}

Cabeça contida de 4 a 4.3 vêzes no comprimento "standard"; altura de 4.3 a 4.8 ; D. 14 ou 15 ; A. 22 a 23 ; P. 14 a 15 ; escamas 38 a 40 ; vértebras 40 .

Corpo mais ou menos elevado, um tanto comprimido lateralmente, com a maior espessura excedendo ligeiramente a altura do pedúnculo caudal; altura contida de 4.3 a 4.8 vêzes no comprimento "standard". Perfis ventral e caudal convexos. Escamas em número de 38 a 40 . Cabeça um tanto grande e alta, com elevação, na articulação da mandíbula, quase igual ao seu comprimento posterior e contida de 4 a 4.3 vêzes no comprimento "standard". Bôca bem rasgada, munida de dentes proeminentes. Maxilar um tanto expandido na porção distal, com margem fortemente arredondada, contida de 1.4 a 1.5 na cabeça, deixando de atingir a articulação da mandíbula por espaço pouco inferior à metade do diâmetro da pupila. Mandíbula contida de 6.0 a 6.2 no comprimento "standard". Focinho curto, medindo eêrea da metade do diâmetro ocular e contido de 5.6 a 6 vêzes na eabeça. Ôlho mais ou menos grande, contido pouco mais de 3 vêzes na eabeça e 1.4 a 1.6 na porção post-orbital da 
cabeça. Opéreulo normal, amplo, formando ângulo agudo na direção da escama axilar da peitoral. Porção post-orbital da cabeça, um tanto curta, contida de 7.9 a 8 vêzes no comprimento "standard". Bochechas curtas e largas, visivelmente menores do que o ôlho, formando ângulo posterior de $60^{\circ}$. Rastros com margens internas fortemente serrilhadas, em número de $20+23$ a 24 no ramo inferior do primeiro areo branquial. Peitoral de tamanho médio, terminando em ponta, com 14 a 15 raios, contida 1.4 na cabeça e de 5.6 a 5.9 vêzes no comprimento "standard". Escama axilar da peitoral comprida, delgada, atingindo a metade do terȩo posterior da peitoral e contida de 1.6 a 1.7 na cabeça. Ventral de tamanho médio, originando-se quase em ponto equidistante da base da peitoral e do local de inserção da anal, contida de 2.5 a 3 vêzes na eabeça. Dorsal um tanto elevada anteriormente, com 14 a 15 raios, implantada em ponto quase equidistante da ponta do focinho e da base da caudal. Anal curta, com 22 a 23 raios, originando-se sob o terȩo distal da dorsal e com a base contida de 4.4 a 4.7 no comprimento "standard". Caudal grande, bem furcada, com lóbulos iguais, terminando em ponta e dotada de pontuações escuras mais acentuadas na base do lóbulo superior.

Colorido creme uniforme; lados da cabeça prateados brilhante; faixa lateral prateada, mais larga no centro do corpo, da largura da pupila, junto ao opéreulo e muito mais estreita perto da caudal.

Comprimento "standard" de 73 a $75 \mathrm{~mm}$. e 95 a $98 \mathrm{~mm}$. de comprimento total.

Distribuição geográfica: Espírito Santo (Vitória).

Anchoviella hubbsi Hildebrand

Est. II, fig. 1

Anchovia manjuba Thering 1930, p. 12; Anchoviella mitchilli 1941, p. 203; Anchovia sp., Carvalho 1943, p. 40; Anchoviella hubbsi Hildebrand 1943, p. 128-129; Anchoviella hubbsi Fowler 1948, p. 20.

Cabeça 4.3 a 4.7 ; altura 4.2 a 5.1 ; D. 14 a 16 ; A. 23 a 26 ; P. 13 ou 14; escamas 40 ou 41 ; vértebras 40 .

Corpo mais ou menos longo, não muito comprimido lateralmente, sua maior espessura excedendo a altura do pedúnculo caudal; altura do corpo contida de 4.2 a 5.1 no comprimento "standard"; perfis dorsal e ventral convexos, êste, porém, bem mais acentuado do que aquêle, sobretudo entre a região gular e o fim da nadadeira anal. Escamas em número de 40 a 41. Cabeça curta, com altura, na articulação da mandíbula, excedendo ligeiramente o comprimento da porȩão post-orbital da cabeça e a metade do ôlho, contida de 4.3 a 4.7 no comprimento "standard". Bôca relativamente pequena, armada de dentes pequenos e recurvados para 
trás. Maxilar provido de expansão distal mais ou menos grande e fortemente arredondado, contido de 1.4 a 1.55 na cabeça. Mandíbula pequena, contida de 6.2 a 6.8 no comprimento "standard". Focinho curto, rombudo, com a metade anterior avançada além da ponta da mandíbula e contido de 4.8 a 5.7 vêzes na eabeça. Olho grande, contido de 3.1 a 3.7 vêzes na cabeça. Opéreulo normal, amplo, eom a margem posterior livre voltada em direção à linha do dorso, sem formar ângulo. Porção post-orbital da cabeça um tanto eurta e contida de 8.3 a 9.6 vêzes no comprimento "standard". Bochechas curtas e largas, com ângulo posterior de $65^{\circ}$. Rastros com a fórmula 18 a $21+22$ a 25 , no ramo inferior do primeiro areo branquial. Peitoral mais ou menos eurta, com 13 ou 14 raios, contida de 1.4 a 1.7 na cabeça e de 6.5 a 7.5 vêzes no comprimento "standard". Escama axilar da peitoral muito comprida, delgada, terminando em ponta aguda e contida de 1.6 a 2 vêzes na cabeça. Ventral pequena, originando-se em ponto quase equidistante da base da peitoral e da origem da anal. Dorsal com 14 a 16 raios, mais ou menos elevada anteriormente, com a margem livre côncava; a maior depressão dá-se entre o $13 .^{\circ}$ e o $14 .^{\circ}$ raio ; origina-se em local quase equidistante da ponta do focinho e da base da caudal. Anal curta, com 23 a 26 raios (em um só caso, num total de 667 exemplares, foram constatados 27 raios), originando-se no meio da base da dorsal, essa base sendo contida de 4 a 4.7 vêzes no comprimento "standard". Caudal ampla, bem furcada, com lóbulos iguais, provida de pontuações escuras, sendo a base do lóbulo superior amarelada.

Colorido branco leitoso uniforme; eabeça denegrida na porção superior; dorso com pontuações escuras; linha lateral prateada, brilhante, estreita nas proximidades do opéreulo, mais larga no meio do corpo, estreitando-se novamente em direção à eaudal; caudal com a base branca, o meio amarelado e os bordos esfumados.

Porte de 98 a $123 \mathrm{~mm}$. de comprimento "standard", podendo atingir até $130 \mathrm{~mm}$. de comprimento total.

Distribuição geográfica: Estado de São Paulo (rio Ribeira de Iguape, até quase Xiririca. Cananéia).

\section{Anchoviella nattereri (Steindachner)}

Engraulis nattereri Steindachner 1880, p. 174-176; Stolephorus nattereri Eigenmann \& Eigenmann 1891, p. 63 ; Anchovia nattereri Jordan \& Seale 1926, p. 413; Anchovia nattereri Thering 1930 , p. 12 ; Anchovia nattereri Campos 1942, p. 208; Anchovia nattereri Fowler 1942, p. 135; Anchoviella nattereri Hildebrand 1943, p. 133; Anchoviella nattereri Fowler 1948, p. 22.

A espécie não foi vista por nós, nem por Hildebrand (1. c., p. 133) que fez um resumo da diagnose de Steindachner. Condensamos a descrição do mesmo autor (Steindachner 1880, p. 174-176) como segue: 
Cabeça 3.33 ; altura 4.0 ; D. 12 ; A. 28-29; escamas, cêrea de 40 .

Corpo esbelto, com a porção infero-anterior que vai do opérculo à anal muito pouco arqueada. Perfil do dorso, na porção anterior da dorsal, mais elevado e abaulado do que a que lhe fica imediatamente oposta; linha ventral provida de quilha acentuada; escamas em número de 40, entre o opéreulo e a caudal, existindo $8 \mathrm{em}$ fileira vertical, acima da anal. Cabeça um tanto eurta, de forma triangular, contida 3.33 vêzes no comprimento; bôca dotada de dentes diminutos e fracos; maxilar curto, com a extremidade posterior descendo quase verticalmente, com os cantos arredondados, não atingindo a articulação da mandíbula; esta provida de numerosos dentinhos. Focinho cônico, comprido, com a ponta embotada, avançando muito além da extremidade da mandíbula e contido 4 vêzes na eabeça; ôlho contido 3.6 vêzes no comprimento da cabeça; porção post-orbital da eabeça, menor do que a peitoral; rastros com comprimento quase igual ao diâmetro do ôlho; peitoral iniciando-se logo atrás da vertical baixada da orla posterior do ôlho, um tanto maior do que a região post-orbital com a ponta alcançando o meio do comprimento da ventral. Dorsal, com 12 raios, situada ligeiramente mais próxima da origem da caudal do que da ponta do focinho, com altura maior do que a da anal; anal com 28 ou 29 raios, iniciando-se sob o meio da base da dorsal; caudal, com altura contida cêca de 2 vêzes na maior altura do corpo, com o lóbulo inferior um tanto mais extenso, pouco menor do que o comprimento da cabeça. Presença de faixa lateral prateada,--bem evidente.

Porte: $50 \mathrm{~mm}$.

Distribuição : Pará.

A descrição de Steindachner não esclarece nada quanto ao opéreulo, bochechas, escama axilar da peitoral, nadadeira ventral, côr, nem ao número de rastros do primeiro areo branquial, particularidade esta que seria de grande utilidade. Quanto à distribuição geográfica, o autor assinala sòmente Pará, sem maiores eselarecimentos.

\section{Anchoviella pallida (Starks)}

Est. II, fig. 2

Anchovia pallida Starks 1913, p. 9; Anchovia pallida Ihering 1930, p. 13; Anchoviella venezuelae Fowler 1931, p. 406; Anchoviella pallida Fowler 1942, p. 134; Anchovia pallida Campos 1942, p. 209; Anchoviella pallida Hildebrand 1943, p. 134; Archoviella pallida Fowler 1948, p. 22.

Cabeça 3.5 ; altura 3.5 ; D. 14 ; A. 24 ; P. 13 ; escamas 38.

Corpo bastante comprimido lateralmente; altura contida 3.5 vêzes no comprimento "standard", com a porẹão peitoral e abominal um tanto 
carenada. O aspecto geral, lembra muito os espécimes do gênero Cetengraulis. Perfil ventral muito mais convexo do que o dorsal; escamas em número de 38. Cabeça um tanto comprida, com altura, na articulação da mandíbula, quase igual ao eomprimento da região post-orbital e a metade do ôlho, contida 3.5 vêzes no comprimento "standard". Bôca bem rasgada, provida de dentes pequenos e uniformes; maxilar forte, contido 1.4 na cabeça e largo, sobretudo na porção posterior; mandíbula forte, menos robusta, porém, do que o maxilar. Focinho um tanto longo, contido 6.4 vêzes na cabeça, com a porȩão anterior avançando de cêrca de $2 / 3$ além da extremidade da mandíbula. ôlho de tamanho médio, contido 4.5 vêzes na eabeça. Opéreulo normal, com a parte superior arredondada, fazendo ângulo acima e abaixo da escama axilar da peitoral. Porção post-orbital da cabeça, de tamanho moderado, contida quase 6 vêzes no comprimento "standard". Bochechas compridas e estreitas, formando ângulo posterior de cêrea de $35^{\circ}$. Rastros delgados, muito unidos, com a fórmula $33-34+44-45$, no primeiro areo branquial. Peitoral comprida, falciforme, terminando em ponta, dotada de 13 raios e contida 5 vêzes no comprimento "standard". Escama axilar da peitoral terminando em ponta aguda, atingindo pouco mais da metade do comprimento da nadadeira, com a porção anterior elevada. Ventral de tamanho médio, originando-se em ponto mais próximo da anal do que da base da peitoral. Dorsal com 14 raios, anteriormente elevada, iniciando-se quase em ponto equidistante da ponta do focinho e da base da caudal. Anal um tanto baixa, começando sob o meio da base da dorsal e contida 3 vêzes e meia no comprimento "standard". Caudal ampla, bem furcada, os lóbulos com as pontas muito finas e as margens enegrecidas.

Colorido branco, leitoso, eom tonalidades prateadas nos lados da cabeça e dorso com pontuações escuras.

Porte de 70 a $80 \mathrm{~mm}$. de comprimento "standard".

Distribuição geográfica: Pará.

\section{Anchoviella jamesi (Jordan \& Seale)}

Fig. II, fig. 3

Anchovia (Amplova) jamesi Thering 1930, p. 11; Amplova jamesi Jordan \& Seale 1926, p. 410; Amplova jamesi Myers 1940, p. 441; Amplova jamesi Fowler 1942, p. 135 ; Anchoviella jamesi Hildebrand 1943, p. 137-138; Anchoviella jamesi Fowler 1948, p. 22.

Cabeça de 4 a 4.5 ; altura de 4.5 a 6 ; D. 12 ou 13 ; A. 19 a 22 ; P. 11, escamas 38 a 40 ; vértebras 39 ou 40 .

Corpo alongado e comprido, com altura contida de 3.5 a 6 vêzes no comprimento "standard"; perfil ventral um tanto mais convexo do que o dorsal; escamas em número de 38 a 40 . Cabeça pequena, contida 
de 4 a 4.5 vêzes no comprimento "standard'"; bôca pequena, com articulação que, geralmente, não ultrapassa a linha baixada da orla posterior do ôlho; maxilar curto, robusto, com a porção distal arredondada e margem inferior curva, contido 2 vêzes na cabeça; mandíbula delgada, contida cêrea de 3 vêzes no comprimento da cabeça. Focinho muito curto, dotado de ponta rombuda e comprimento quase igual ao da metade do diâmetro do ôlho, contido pouco mais de 7 vêzes na cabeça. Ôlho grande, anterior, contido de 3.2 a 3.8 vêzes na eabeça. Opéreulo provido de reentrância mais ou menos acentuada entre a faixa lateral e a nadadeira peitoral; porção post-orbital da cabeça mal definida; bochechas curtas, com a margem infero-posterior mais ou menos arredondada. Rastros delgados, com a fórmula $12-13+20$ a 21 , no primeiro arco. Peitoral grande, com 11 raios, contida cêrea de 5 vêzes no comprimento "standard". Ventral mais ou menos ampla, originando-se quase que em ponto equidistante da base da peitoral e do ponto de origem da anal. Dorsal mais ou menos alta anteriormente, com 12 a 13 raios, iniciando-se quase em ponto equitistante do meio da região post-orbital e da base da caudal. Anal de tamanho médio, com 19 a 22 raios, um tanto elevada anteriormente e contida de 4.2 a 5.2 vêzes no comprimento "standard". Caudal furcada, com as pontas dos lóbulos arredondadas.

Colorido branco, leitoso. Faixa lateral prateada difusa, começando muito estreita, no bordo superior do opérculo, alargando-se um pouco a partir do fim do terço anterior do corpo para finalizar com maior largura, posto que pouco distinta, junto ao pedúnculo caudal.

Porte de 32 a $37 \mathrm{~mm}$. de comprimento "standard".

Distribuição geográfica: Amazonas (lago Aleixo).

\section{Anchoviella hildebrandi Carvalho}

Est. II, fig. 4

Anchoviella hildebrandi Carvalho, 1950, p. 77-81, fig. 1

Cabeça 3.9 a 4.6 ; altura 4.1 a 4.9 ; D. 17-18; A. 19-20; vértebras $40-41$.

Corpo delgado, comprido, bastante comprimido lateralmente, com maior altura ao nível da nadadeira dorsal; perfil do dorso quase paralelo ao do ventre, apresentando-se êste ligeiramente convexo entre a porção posterior da anal e o mento; cabeça curta, com altura contida 1.4 a 1.5 no seu comprimento, junto da articulação da mandíbula; bôca pequena, com denticulação muito fina no maxilar; maxilar muito eurto, com a porção final expandida e arredondada, avançando pouco além da margem posterior da órbita, em distância igual à metade do diâmetro da pupila, não alcançando a articulação da mandíbula e contido 1.6 a 1.8 na cabeça; mandíbula contida de 1.3 a 1.7 na eabeça; focinho curto, ligeiramente 
pontudo, contido de 3.75 a 5.8 na cabeça; narinas contíguas; ôlho grande, contido de 2.5 a 3.5 na eabeça; opéreulo formando ligeiro ângulo logo abaixo da faixa lateral prateada; subopéreulo normal; poręão post-orbital da cabeça contida de 1.9 a 2.3 no comprimento; bochechas mais longas do que largas, com ângulo posterior bem definido; rastros mais longos do que o diâmetro do ôlho, com a fórmula $17-20+20-25$, no primeiro areo branquial; nadadeira peitoral deixando de atingir a ventral por distância superior à que vai da ponta do focinho à margem posterior da órbita, contida de 1.5 a 1.8 na cabeça e de 7.0 a 7.7 no comprimento "standard"; escama axilar da peitoral igual à altura da cabeça e contida 2 a 2.1 no comprimento desta; ventral curta, inserida mais perto da anal do que da base da peitoral, com comprimento equivalente à altura do pedúnculo caudal; dorsal moderadamente elevada na porção anterior, com os raios mais longos não atingindo a ponta do último raio, quando a nadadeira se encontra defletida, originando-se em ponto quase equidistante da ponta do focinho e da base da caudal; inserção do primeiro acúleo da anal sob os raios mais posteriores da dorsal, sendo a sua base contida de 5.5 a 6.3 no comprimento "standard"; caudal amplamente furcada.

Colorido creme, com lista lateral prateada bem evidente, mais estreita no terço anterior, alargando-se a partir do meio da dorsal, não sendo, porém, em qualquer parte, mais larga do que o diâmetro do ôlho; parte postero-superior do opéreulo com uma zona irregular, mais clara, como se fôsse mancha prateada brilhante; no mento e no abdomen, notam-se iridescências prateadas, por vêzes muito pronunciadas, que desaparecem ou apenas se tornam menos intensas nos exemplares submetidos à ação de líquidos fixadores. Dorso e eabeça com pontuações escuras, formando, nesta, duas máculas ovais, bem destacadas, na linha de sua intercessão com o lombo; ao longo do dorso existem também manchas escuras, pequeninas e esparsas; nadadeira caudal com a base e os ramos externos eseurecidos.

A espécie é muito próxima de Anchoviella brasiliensis Hildebrand e de $A$. jamesi Jordan \& Seale.

Porte de 65 a $72 \mathrm{~mm}$. de comprimento "standard".

Distribuição geográfica: Rio Paraguaçú (Bahia).

\section{Anchoviella brasiliensis Hildebrand}

Est. II, fig. 5

Anchoviella (Amplova) sp., Carvalho 1943, p. 41; Anchoviella brasiliensis Hildebrand 1943, p. 138-139; Anchoviella brasiliensis Fowler 1948, p. 20.

Cabeça 4.4 a 4.6 ; altura 5.7 a 6.1 ; D. 12 a 13 ; A. 19 ; P. 14 a 15 ; eseamas, cêrea de 44 ; vértebras 40 a 41 . 
Corpo um tanto alongado e bastante comprimido lateralmente, sendo sua maior espessura igual à altura do pendúneulo caudal; altura contida de 5.7 a 6.1 no comprimento "standard"; perfil dorsal quase igual ao ventral, formando ligeira concavidade a partir da origem da anal, até quase o início do pedúnculo caudal; escamas em número de cêrea de 44 . Cabeça curta, contida de 4.4 a 4.6 vêzes no comprimento "standard", sua altura, na articulação da mandíbula, sendo igual à porção post-orbital da cabeça; bôca pequena, mais ou menos bem rasgada; maxilar muito curto, com a extremidade posterior arredondada, sendo aí bem mais largo; comprimento do maxilar contido de 1.65 a 1.7 na cabeça; mandíbula, de certa amplitude, contida cêrea de 6.7 vêzes no comprimento "standard". Focinho muito curto, avançando ligeiramente além da ponta da mandíbula e contido de 5.4 a 5.7 vêzes na cabeça; ôlho grande, situado mais próximo do alto da cabeça e nesta contido de 3 a 3.2 vêzes. Opéreulo normal, descendo quase em linha reta, em direção à região gular, a partir do ponto de origem da escama axilar da peitoral; porção post-orbital da cabeça curta, contida de 9.4 a 9.7 no comprimento "standard"'; bochechas mais largas do que compridas, muito menores do que o ôlho, sem ângulo posterior definido. Rastros com a fórmula $17-24+17-25$, no primeiro areo branquial. Peitoral pequena, eom 14 ou 15 raios, contida de 7.2 a 7.4 no comprimento "standard"; escama axilar da peitoral longa, atingindo quase a ponta da nadadeira e contida de 2 a 2.8 vêzes na cabeça; ventral um tanto comprida, dotada de eseama axilar, inserida mais perto da anal do que da base da peitoral; dorsal com 12 ou 13 raios, com a parte anterior mais elevada, originando-se em ponto quase equidistante da ponta do focinho e da base da caudal; anal com 19 raios, pequena, originando-se em ponto um tanto posterior ao meio da base da dorsal e contida de 5.7 a 5.9 no comprimento "standard". Caudal bem furcada e ampla, com base escurecida.

Colorido branco leitoso, com o dorso pintalgado por pontuações negras; ôlho com a iris provida de tonalidades avermelhadas. Ausência de faixa lateral evidente.

Porte de 60 a $62 \mathrm{~mm}$. de comprimento "standard".

Distribuição geográfica: Estado de S. Paulo (Rio Ribeira de Iguape).

\section{SUMÁRIO}

Nos anos de 1948-49, o autor teve ocasião de estudar os representantes da família Engraulidae que frequentam a costa brasileira, pesquisa essa supervisionada gentilmente pelo Dr. Samuel F. Hildebrand, ictiólogo do U. S. Fish \& Wildlife Service, de Washington.

Dessa investigação resultou a conveniência de se identificar e redeserever as espécies que fazem parte das eoleções do Instituto Paulista de Oceanografia. 
O presente trabalho é, pois, baseado na revisão das manjubas americanas publicada pelo Dr. Hildebrand em 1943 e no trabalho em que figurou como co-autor: "Notes on some Brazilian anchovies (Family Engraulidae) with description of four new species" (1948).

Graças à gentileza do Dr. Hildebrand, foi examinada uma coleção extensa do Museu Nacional dos Estados Unidos. De inestimável valor foi a manipulação de exemplares constantes da eoleção do Dr. W. C. Schroeder, do Museu de Zoologia Comparada, especialmente rica em exemplares do Brasil. O autor muito deve ao Dr. Hildebrand pelo trabalho enorme desenvolvido nesse sentido.

No texto, obedeceu-se a sequência sempre uniforme quanto aos caractéres peculiares a cada espécie, de modo a facilitar o estudo, por parte de outras pessoas interessadas no grupo.

A distribuição geográfica dos espécimes aqui considerados figura no Mapa n. $^{0} 1$.

\section{SUMMARY}

In 1948-1949, the author studied the Brazilian Engraulidae of the genus Anchoviella, under the supervision of the late Dr. Samuel F. Hildebrand, ichthyologist of the U. S. Fish \& Wildlife Service, Washington.

It has been found desirable to undertake the identification and redescription of the Brazilian Anchovies from the collections of the Instituto Paulista de Oceanografia (São Paulo Oceanographic Institute).

This work is then based in the review of the American anchovies published in 1943 by Dr. Hildebrand and in the paper where the author figure as "junior author": "Notes on sobe Brazilian anchovies (Family Engraulidae) with description of four new species" (1948).

Through the courtesy of Dr. Hildebrand, a very extensive collection of the U. S. National Museum was available for comparison and study. The principal collection examined was that of Dr. W. C. Schroeder, of the Museum of Comparative Zoology, especially rich in specimens from Brazil.

The sequence of characters used in the redeseriptions is fairly uniform that is, the various characteres commonly reported are named in the same order. This uniform sequence was carried out for the convenience of the student who in using the paper should soon learn where to look the redescription of any particular character he may wish to check.

The geographical distribution of the specimens here considered is shown on the accompanying Map. 


\section{BIBLIOGRAFIA}

ANUÁRIO DA PESCA MARítIMA NO ESTADO DE S. PAULO, 1944 - Secretaria da Agricultura, Divisão de Proteção e Produção de Peixes e Animais Silvestres, p. 1-122. S. Paulo.

CAMPOS, A. DO A., 1941 - Contribuição ao estudo dos clupé́ides das águas brasileiras. Arq. Zoologia S. Paulo, Vol. 13, art. 7, p. 185-218, Est. I-IX. S. Paulo.

CARVALHO, J. DE P., \& RAMOS, F. DE P. A., 1943 - O desenvolvimento da pesea e a industrialização da manjuba, no rio Ribeira. Bol. Ind. Animal, p. 38-59. S. Paulo.

CARVALHO, J. DE P., 1943 - Nota preliminar sôbre a fauna ietiológiea do litoral sul do Est. de S. Paulo. Bol. Ind. Animal, n. ${ }^{\circ}$ 150, p. 1-81. S. Paulo.

CARVAlHo, J. DE P., 1950 - Engraulídeos brasileiros do gênero Anchoa. Bol. Inst. Paulista de Oceanografia, Vol. I, n. ${ }^{\circ}$ 2, p. 43-69, Est. I-II. S. Paulo.

DIVISÃO DE EXPERIMENTAÇÃO E PESQUISAS, 1949 - Seminários de Estatística Aplicada, p. 1-97. Inst. Agronômico. Secretaria da Agricultura. Dep. Prod. Vegetal. Campinas.

EIGENMANN, C. M., \& ALLEN, W. R., 1942 - Fishes of Western South America - I - The Intereordilleran and Amazonian Lowlands of Peru. Il The high pampas of Peru, Bolivia and Northern Chile. With a revision of the Peruvian Gymnotidae, and of the genus Orestias, XV +494 p., 1 mapa, est. I-XXIII. Lexington-Kentuchy.

EIGENMANN, C. H., \& NORRIS, A. A., 1900 - Sôbre alguns peixes de S. Paulo, Brazil. Contr. Lab. Zool. Univ. Indiana, n. ${ }^{\circ} 33$, Rev. Mus. Paulista, vol. IV, p. 349-362. S. Paulo.

FOWLER, H. W., 1931 - Fishes obtained by the Barber Asphalt Company in Trinidad and Venezuela, in 1930. Proe. Acad. Nat. Sci. Phil., Vol. 83, p. 391-410, 6 fig. Philadelphia.

FOWLER, H. W., 1941 - Zoological results of the seeond Bolivian expedition for the Acad. Nat. Sei. Phil., I - Fishes. Proc. Acad. Nat. Sei. Phil., Vol. 92, p. 43-103, 52 figs. Philadelphia.

FOWLER, H. W., 1942 - A list of fishes known from the coast of Brazil. Areh. Zool., Vol. 3, p. 115-184. S. Paulo.

FOWLER, H. W., 1948 - Os Peixes de água doce do Brasil. Arq. Zool., vol. VI, p. 1-204. S. Paulo.

GUNTHER, A., 1868 - Catalog of Fishes of the British Museum, Vol. 7, p. 1-512, London.

HILDEBRAND, S. F., 1943 - A Review of the American Anchovies (Family Engraulidae). Bull. Bingham Oceanogr. Coll., (VIII), p. 1-165. New Haven.

HILDEBRAND, S. F. \& CARVALHO, J. DE P., 1948 - Notes on some Brazilian Anchovies (Family Engraulidae) with descriptions of four new species. Copeia, Vol. 4, p. 285-296. Ann Arbor.

IHERING, H. VON, 1897 - Os peixes da costa do mar no Estado do R. G. do Sul. Rev. Mus. Paulista, Vol. II, p. 25-63. S. Paulo.

IHERING, R. VON, 1930 - As Sardinhas e Manjubas brasileiras. Seu valor econômico e noções de systematica. Rev. Ind. Animal, Vol. 3, p. 221-234. S. Paulo.

JORDAN, D. S., \& SEALE, A., 1926 - Review of the Engraulidae, with descriptions of new and rare species. Bull. Mus. Comp. Zool., Vol. 67, n. ${ }^{\circ} 11$, p. 355-418. Cambridge. 
LE COINTE, P., 1945 - o Estado do Pará - A Terra, a água, o ar. Ed. ilustr., IX +303 p. S. Paulo.

MAGALHÃES, E., 1942 - A pesea do Xaréu, a eriação de um entreposto na Bahia e a situação da pesca e aproveitamento do surubim no rio São Franciseo. Separata do Bol. Minist. Agrie., p. 1-23. R. de Janeiro.

MYERS, G. S., 1940 - The neotropical anchovies of the genus Amplova. Proc. Cal. Acad. Sci., Ser. 4, Vol. 23, p. 437-442. California.

REGO, L. F. DE M., 1936 - O Valle do S. Franciseo (Prêmio Capistrano de Abreu de 1935). Rev. Mus. Paulista, Vol. XX, p. 491-706. S. Paulo.

STARKS, E. C., 1913 - The fishes of the Stanford expedition to Brazil. Stanford Univ. Publ., Univ. Ser., p. 1-77, 14 est. Stanford. California.

STEINDACHNER, F., 1908 - Über zwei neue Fisharten aus dem Stromgebiete des Rio S. Francisco. Anz. Akad. Wiss. Wien. Vol. 45, p. 191-194.

STEINDACHNER, F. 1880 - Iehthyologische Beitrage (VIII). Sitzb. Kaiser Akad. Wiss Wien, Vol. 80 , p. 119-190, taf. I-III.

STOREY, M., 1938 - West Indian Clupeid fishes of the genus Harengula with notes on $H$. thrissina from the Pacific coast. Stanford Iehthyological Bull., Vol. I, n. ${ }^{\circ}$, p. 1-56. Stanford.

STEVENS, W. L., 1950 - Desenvolvimentos modernos do delineamento de experiências. Parte I. "Ciêneia e Cultura", p. 17-28, vol. 2, n. 1. S. Paulo.

TEIXEIRA, E. F., 1950 - As riquezas do litoral paulista. Assuntos agrícolas, em "O Estado de S. Paulo", de 5 de Abril de 1950. S. Paulo.

VERISSIMO, J., 1895 - A pesea na Amazônia. Monographias Brasileiras III, p. 1-206. S. Paulo - R. de Janeiro. 


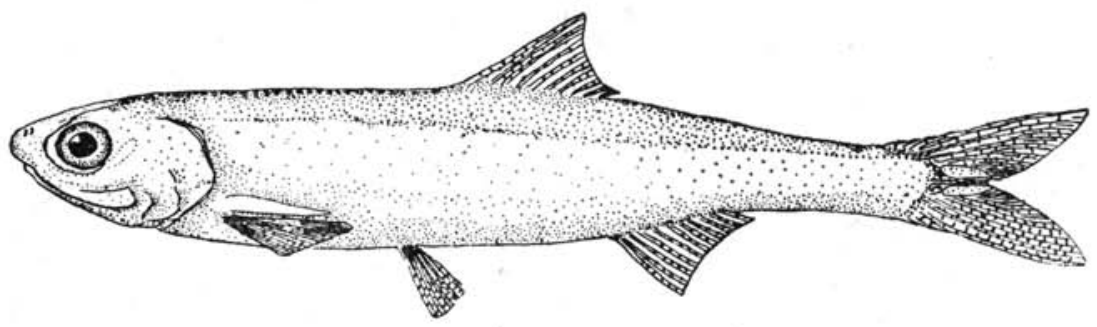

Fig. 1

Anchoviella victoriae. De um espécime medindo $110 \mathrm{~mm}$. Vitória. Estado do Espírito Santo.

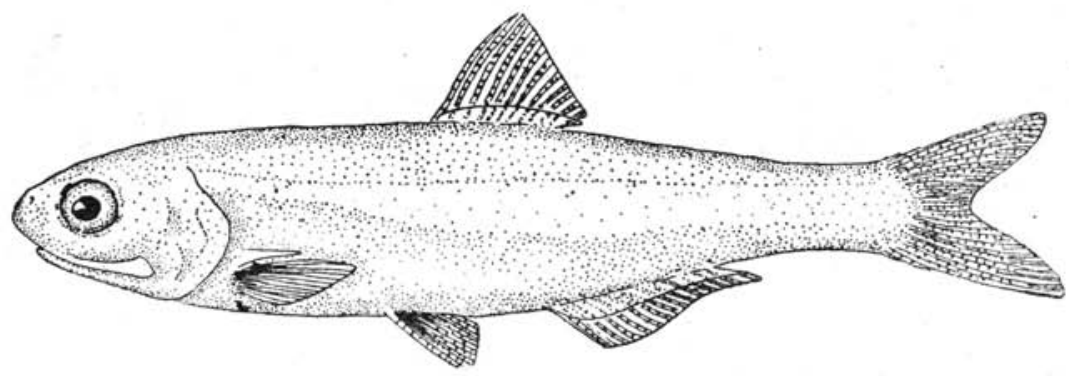

Fig. 2

Anchoviella brevirostris. Espécime medindo $86 \mathrm{~mm}$. Caxoeira. Estado da Bahia.

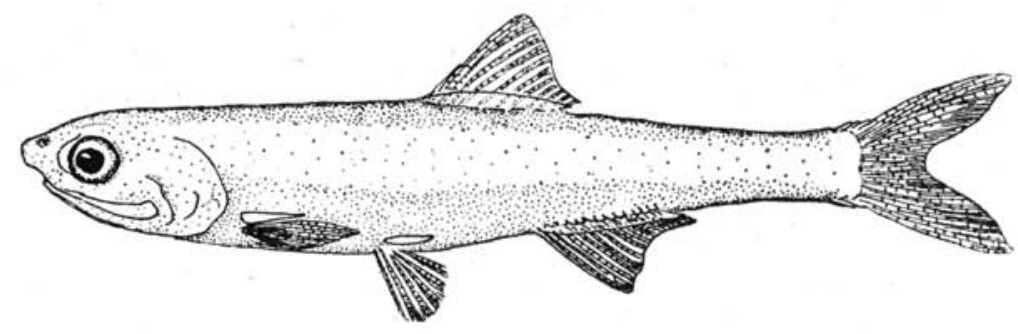

Fig. 3

Anchoviella guianensis. Espécime de $60 \mathrm{~mm}$. Estado do Amazonas.

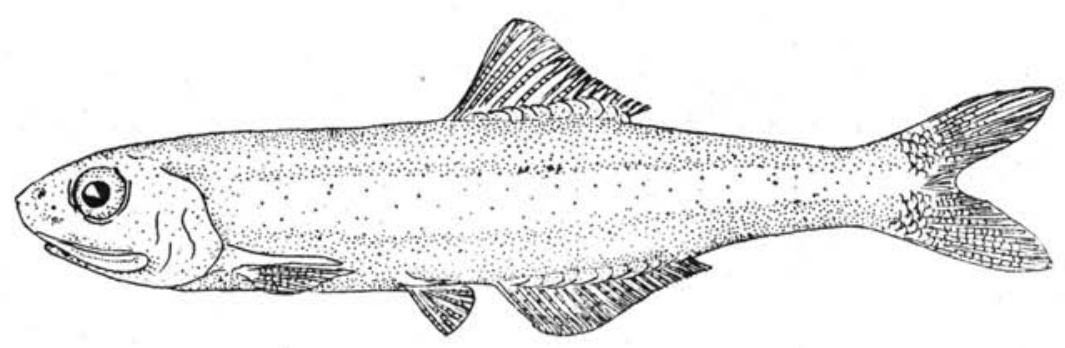

Fig. 4

Anchoviella iheringi. Exemplar de $100 \mathrm{~mm}$.

Rio Jaguaribe. Estado do Ceará. 


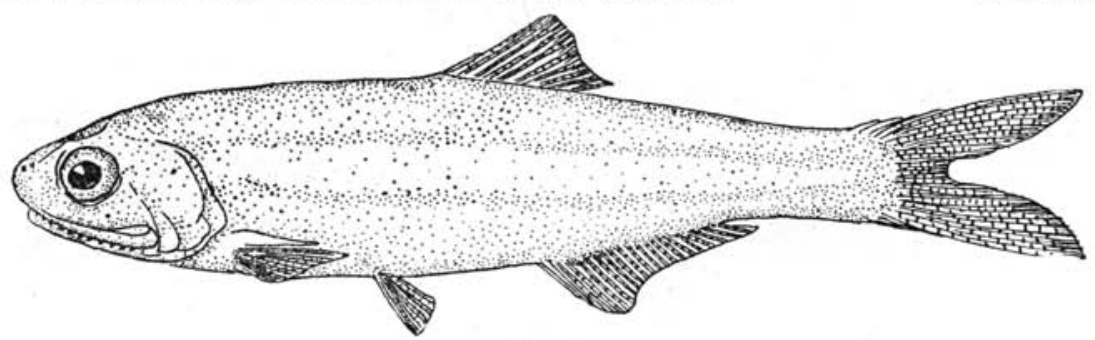

Fig, 1

Anchoviella nitida. Exemplar medindo $76 \mathrm{~mm}$. Vitoria. Estado do Espírito Santo.

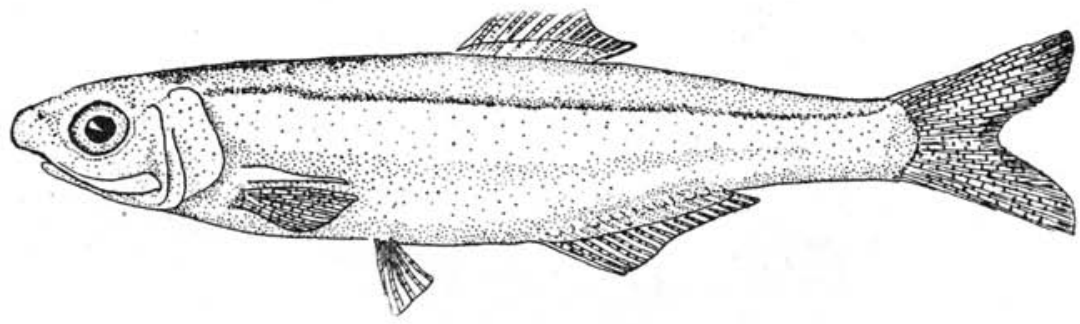

Fig. 2

Anchoviella hubbsi. Exemplar medindo $120 \mathrm{~mm}$. Rio Ribeira de Iguape (Registro). E. de S. Paulo.

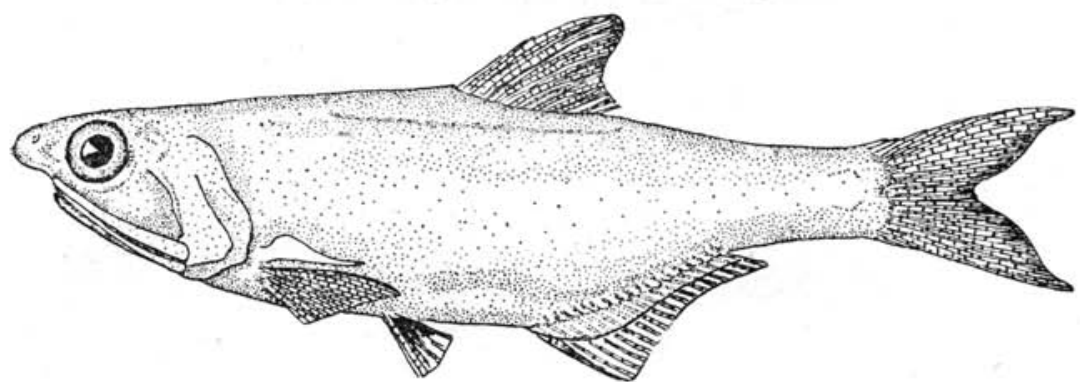

Fig, 3

Anchoviella pallida. Exemplar medindo $100 \mathrm{~mm}$. Estado do Pará.

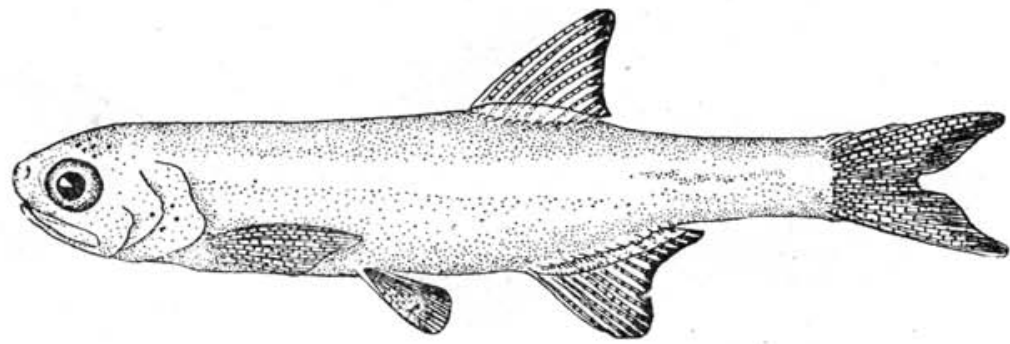

Fig. 4

Anchoviella jamesi. Exemplar medindo $36 \mathrm{~mm}$. Estado do Amazonas. 